\title{
COVID-19 Solar Disinfectant in Kuthambakkam, India - A Model of the Framework for Strategic Sustainable Development in Marginalised Communities
}

\author{
D. R. Broman ${ }^{1} \&$ Dhivya M Ilango ${ }^{2}$ \\ ${ }^{1}$ International Program in Climate Change and Sustainable Development, National Taiwan University, Taiwan \\ ${ }^{2}$ Faculty of Business \& Sustainable Development, University of Seychelles, Seychelles \\ Correspondence: David Broman, International Program in Climate Change and Sustainable Development, \\ National Taiwan University, Taiwan. Tel: 886-9-1941-4462. E-mail: davidryanbroman@gmail.com
}

Received: July 27, 2020

doi:10.5539/jsd.v13n5p46

\author{
Accepted: August 17, 2020 \\ Online Published: September 28, 2020
}

URL: https://doi.org/10.5539/jsd.v13n5p46

\begin{abstract}
Using the Framework for Strategic Sustainable Development (FSSD) as an analytical tool, this work examines the sustainability decision making in an Indian village. Kuthambakkam - through the efforts of Elango Rangasamy has become a site of value for understanding how sustainable development concepts can be applied successfully in an actual developing world scenario. The FSSD, including the concepts of 'The Funnel', back-casting and the principle based definition are used to analyse the Kuthambakkam case. This identifies how the decision-making process and actions in the panchayat provide a unique and valuable model of leadership for sustainability - with well-being as a goal. A decentralised, solar-powered disinfectant production method pioneered by Elango is the main project that is examined for this article. The model is currently operated by women's self help groups in several locations within and nearby to the village - including a large scale production at a vital vegetable market. As the priority of the leadership - or end goal of the funnel - is the well-being of disadvantaged people, the results show superior alignment with sustainability principles compared to decisions made by leaders in corporations and the developed world.
\end{abstract}

Keywords: sustainability leadership, marginalised community development, holistic well-being, horizontal growth, low-cost virus disinfectant

\section{Introduction}

There is much discussion in academia, the political world and more recently in the mainstream media regarding the effective course of action to adapt to and mitigate the oncoming risks caused by anthropogenic climate change. International regulatory bodies have progressively turned their attention to the push on governments to create more effective policy (Masson-Delmotte, et al, 2018) (Beck \& Mahoney, 2018) - in response to the increasingly uncertain threats caused by ongoing increase of emissions (Xu, Ramanathan \& Victor, 2018). Several nations provide a road map for the supposed carbon-neutral future, such as Costa Rica (Godinez, 2020) and Iceland (Clarke, 2017), but these show that a simple de-escalation of carbon reliant energy systems is not sufficient (Kristjansdottir \& Busch, 2014). A societal change is also required for a truly carbon neutral society. Even the most ambitious targets - if met, provide no guarantee of a continuation of human life on earth much as it has for the last century of excess and greed (Kennedy, 2018). Things need to change and there is a growing wave of understanding that this is the case (Dankelmann, 2010) (Llavador, Roemer \& Silvistre 2015) (Matson, Clarke \& Andersson 2016) (Wapner \& Elver, 2016).

The recent global health pandemic created by COVID-19 requires a momentous reaction from governments and health institutions (Sohrabi, Eds, 2020). This reaction can be compared to the type of behavioural changes that are required for humans to respond effectively to global warming and other climate related issues. Swift and widesweeping policy change, shift in cultural mindset of the population, adjusting lifestyle and practices to meet new challenges - these are all consistent with the response to COVID-19 and what is the necessary response to climate change (Delina, 2016). The leadership and decision making in the case of Kuthambakkam - in response to COVID19 - is an example of how effective leadership for sustainable development can rapidly respond to changing needs.

Theoretical research into leadership for sustainable development is predominantly focused in the professional 
sector of developing countries (Metcalf \& Benn, 2013) (Quinn \& Dalton, 2009) (Johnson, Hays, Center, Daley 2004) (Szekely \& Knirsch, 2005). Both corporate (Roos, 2017) and government (Heizmann, 2018) (Bratt, Hallstedt, Robert, Broman \& Oldmark 2013) leadership have been the focus of various studies to understand how to improve leadership toward sustainability targets. There is also a field of research that covers leadership for sustainability within education (Hargreaves \& Fink, 2003, 2004). This is primarily focused on how educators can lead the way towards a sustainable future - somewhat on the leadership for sustainability from within education institutions (Bottery, 2016). Education sustainability is more focused on leadership of learners, rather than employees or the constituency. Leadership of employees and electorates is the focus of this article.

The body of research on leadership for sustainability that does exist is based on cases where profit-making is a significant priority in the decision making process. In studies of leadership for sustainability from within governments, the cases are in developed countries - where the needs for sustainability are heavily influenced by the desire to maintain economic growth. These developed countries also demand the maintenance of opulent lifestyles - which are difficult to uphold in the push towards a sustainable future.

The leadership for sustainability in the case of Kuthambakkam provides an example where profit-making, upward growth or opulence are not the focus of the decision-making process. In this case it is the well-being of the most disadvantaged groups that drives the decisions. Improving the well-being of disadvantaged people is the vision that guides the decisions on how various products will be designed and how the projects for producing and distributing these products will be managed. This is done so to empower the people who are most at need. Rather than an endless upward growth for a few - there is a push for 'horizontal growth' (Elango, personal communication, July 25 2019) for many. For this reason, the case of Kuthambakkam provides a unique and valuable example of how leadership for sustainability can operate in the most at-need environments.

The Framework for Strategic Sustainable Development is a tool developed by a group of researchers in Sweden (Broman \& Robert, 2017). The goal of the FSSD is to provide decision makers with an aide to support the achievement of more sustainable outcomes. Thus far, the FSSD has been utilised by companies and local governments in the region where the tool was developed. Scandinavia and north-western European nations have a well-regarded capacity for socialist style - highly functional decision making. The examples of the FSSD being used in practical decision making context are limited to the developed world - and within that, a highly successful region of development. Until now, there has been no efforts to analyse how the decision making of a highly successful case of sustainable development from within the developing world can be understood through such a tool.

India is still in the grips of the novel coronavirus (COVID-19), the full impact of the virus in India is yet to be fully realised as this article is being written. Without question - the risk of this virus is extremely high in the context of India and other developing world nations (Khan, 2020). The widespread extreme poverty, inconsistent and often dysfunctional approach to hygiene (Anuradha, Eds, 2017), the enormous population and a lack of effective public health infrastructure all add to the risk of COVID-19 having a devastating impact in countries like India.

As an immediate response to the global health pandemic a decentralised production of disinfectant was developed. This low-cost production model is designed to be distributed to resource poor communities. The process requires easily accessible materials and utilises solar energy. It provides a low-cost option for the most disadvantaged residents.

The style of leadership and decision-making to develop this production method is consistent across a wide variety of projects pioneered by Elango and the Trust for Village Self-Governance (TVSG) over the last 25 years. Like much of Elango's work, the goal of this project is to improve the well-being of the most disadvantaged members of society (Elango, personal communication, July 25 2019). When this decision making process is examined using the FSSD concepts as an analytical framework - it shows the highly sustainable nature of these efforts. It is apparent similar concepts as the FSSD promotes are being used- but the vision from which is being back-casted is quite different from that which the other practical examples of the FSSD provide. The goal of the decision making process is the improvement in well-being of the most disadvantaged and marginalised groups in society. Therefore, the sustainable virtues of these decisions are significant, worthy of deeper investigation, and offer considerable value to others looking to make decisions with a more sustainable outcome - both in the developing and developed world context. 


\section{Sustainable Development in Kuthambakkam}

\subsection{Why Kuthambakkam?}

Kuthambakkam is a small group of hamlets around $35 \mathrm{~km}$ south east of downtown Chennai. It is nestled between major freeway routes that carry goods and people to and from the major trading and commercial hub. The population of Kuthambakkam is 6000 people, spread across three main hamlets and a range of small clusters set amongst the farms. Chennai is around a 90-minute drive in good traffic. The nearer town of Poonamallee is about 25 minutes away and provides all the modern commerce that India offers.

Once you veer off the highways and onto the roads managed by the local government - there is an immediate change of pace. It is very apparent that village life has not yet been overrun by the imposing urbanisation. Elango will often quote Mahatma Gandhi and a relevant one here is that "India lives in it's villages, if villages perish India will perish" (Elango, personal communication, July 25 2019)

In 1993 the government of India passed the $73^{\text {rd }}$ constitutional amendment (Singh, 1994). This provided opportunity for local people to govern their villages in a system known as the 'panchayat'. Panchayat is an ancient form of local self-governance - the traditional meaning is 'group of five' - experts or leaders who would make decisions for the village in ancient times (Elango, personal communication, July 25 2019). With the $73^{\text {rd }}$ amendment, the panchayat system was introduced as a decentralised local self-governance framework whereby villagers could make decisions about their own lives. Elango was elected president of the first Kuthambakkam panchayat in 1995 . He served two consecutive 5 year terms. In the first term there was a transformation in the village, particularly for the extremely poor and economically marginalised Dalit community where Elango was raised. During his second term, the sustainable change in the village began to receive attention from within India and from international development bodies.

Since this time Elango has worked with the Trust for Village Self Governance (TVSG) he established. This is a not-for-profit organisation set up to continue the works within the village and most importantly to build on efforts to support sustainable development in the established network of panchayats. The TVSG also operates the Panchayat Academy - a learning institute developed to provide other panchayat leaders a place to improve their capacity and understanding of leadership through the panchayat system. The TVSG can manage projects that deliver services in the village, and also can offer support to other villages to learn the techniques and install products TVSG have designed. The Panchayat Academy trains other village leaders and student groups in the philosophy and practices that have led to the success in this case. Through these mechanisms, the Kuthambakkam model has been exposed to hundreds of of panchayat's and many thousands of students and villagers.

There are several articles that describe the social and economic conditions in Kuthambakkam in more detail (Poonamallee, 2007) (Raju \& Dwivedula, 2009) (Gram Vikas). The network-economic-growth (Cajka, 2014) (Kothari, 2018) is a key feature of the Kuthambakkam model. This involves the sharing of resources between farmers and producers. The model limits the amount of goods purchased from outside the network of villagers, and maximises the cost benefit ratio for the most disadvantaged.

For the purpose of this article, it is important to understand that Kuthambakkam is very much a reflection of village life in India. This is no coincidence as Elango openly values and wishes to have sustainable development based in the villages of India. He actively promotes Kuthambakkam as a model for village life. A powerful component of that representation is that people from other villages who come to see the model must see it as a familiar environment to their own home. Elango does not promote measures that will urbanise the village.

In 2013 India was assessed to be home for $27 \%$ of the world's poor (Page \& Pande, 2018). Given that approximately $70 \%$ of India's 1.3 Billion population live in villages (Press Trust of India, 2013), sustainable development in Indian villages is perhaps the most valuable endeavour in efforts to address global poverty.

The value in the Kuthambakkam case comes from the amount of time the model has been developed and the variety of projects that Elango has successfully tackled on his path towards a sustainable village. In this article it is argued that well-being is the key outcome of the decision making process. In particular, it is the well-being of the most marginalised and disadvantaged groups that are the key focus of the issue that the project or product is designed is trying to solve. With this in mind, it is vital to understand the value of the initial stage of the development process - how this continues to have ripple-effects throughout the village, and via his teachings in the Panchayat Academy. When Elango took office as President of the Kuthambakkam Panchayat - the village had many social dysfunctions as a result of the illicit alcohol brewing that plagued the area and the problems that come with rampant alcoholism. This was the biggest barrier to ensuring the well-being of the constituency. 


\subsection{Eradicate Illegal Alcohol}

The first phase of development in Kuthambakkam was the eradication of illegal alcohol brewing by some of the local Dalit families. The cheap access to high octane liquor and lack of opportunity led to significant social problems, as is the trend. As one local, former brewer, of Kuthambakkam stated "things were very bad before he (Elango) came.. after the panchayat started, he built roads, improved the schools and and created more opportunities.. this meant we were able to stop brewing.." (Thomas, 2019)

With low levels of education and little opportunity, alcohol brewing was a reliable, but risky, source of income for the local Dalit. The frequent police harassment/corruption and the social dysfunction associated with having drunks around constantly meant that it wasn't long before the former brewers were happy and proud to be employed in respectable work. It is clear to see in their faces when they talk about the old days, they are very happy not to be living in the stressful and desperate world of drunken fuelled poverty. Although they may not be living in an income bracket of any comparison, they certainly seem more content and peaceful than your average resident of a Western city. Nowadays, not only do their children complete secondary schooling, the majority also go to college.

The case of Kuthambakkam not only provides an outstanding model for other panchayat's to learn from and adapt to their own needs - it is also a source of knowledge for global efforts toward sustainable development. As Western societies transition toward a sustainable future, and the community participation required grows and develops, the practice of 'demystifying technology' (Elango, personal communication, July 252019 ) and simple but effective solutions will become more valued. Kuthambakkam continues to develop solutions to problems for Indian villages, absolutely aligned with the principle based definitions of sustainable development in the Framework for Strategic Sustainable Development.

\section{Methodology}

The case of Kuthambakkam has received much international recognition over the last 15 years. The success in this case is well supported with significant quantitative data, collected by the state and provincial government apparatus, via internal functions of the panchayat and through various researchers who have visited. The goal of the field trip conducted by this research group was to gather qualitative evidence to understand the case study - specifically in regards to the applications for sustainable development in marginalised and disadvantaged communities.

The methodology for this research is based on the constructivist paradigm (Stake, 1995) (Yin, 2003) which allows for participants to express their own perceptions of reality based on their constructions. The approach to the case study was an exploratory method - which is used to "explore those situations in which the intervention being evaluated has no clear, single set of outcomes" (Baxter \& Jack, 2008). The exploratory approach was used to understand what impacts have been experienced by the disadvantaged and marginalised members of the community. To figure how this case study can provide a pathway for others seeking to achieve sustainable development, the researchers used the instrumental (Stake, 1995) style of case study research. This approach "provides insight into an issue or helps to refine a theory" (Stake, 1995). In this case the researchers are trying to understand how to address the issue of unsustainable practice in disadvantaged communities, and to refine theories related to a concept of Sustainable Holistic Economic Development.

Field work methodology used for this research would appear similar to the methodology of qualitative ethnographic research. The actual field practice is influenced by the work of Stenbecka (2001) - who is one of the new wave of qualitative research theorists breaking down traditional boundaries. This method differs from qualitative ethnographic research as the goal is to understand the practices within the community, and how these contribute to sustainable development goals - rather than the cultural interactions and intricacies of the community, and how these also have changed as a result of the development process. In this regard, the process of understanding the practices and activities of the TVSG, Panchayat Academy and other systemic operations of sustainability, is more similar to a business case analysis.

The inductive approach to understanding the results of the research was taken in this case study. The inductive approach draws from the results, rather than gathering evidence in an attempt to prove something. The success in the case of Kuthambakkam has been proven, the goal of this research is to understand what elements can be drawn from this successful case for others to learn and benefit their own communities. One of the findings drawn from the research project was the quality of the sustainably minded decision making process. The focus of the decision making of this research was particularly in regards to the products and material items that are designed and built through the TVSG. Of the many theories drawn from the evidence gathered during the qualitative field work, the leadership and decision making that generates sustainability minded results and products is the key finding for this article. 


\section{The Framework for Strategic Sustainable Development - Definition}

The Framework for Strategic Sustainable Development (FSSD) is the outcome of over 25-years research including a gather of input from a great variety of academic and professional disciplines. The nature of the FSSD is designed to be complimentary to other tools for sustainable development planning. As a leadership aide, it is predominantly utilised by leaders in positions of power and wealth. The existing examples of it's application come from highlevel corporate and government decision-making groups. It is fair to say the FSSD is most commonly used by profit makers to work towards sustainability for their organisation - with the understanding of the link to sustainability for the whole planet.

The FSSD gives us 'The Funnel' metaphor as a representation of decision-making towards a sustainable outcome. A basic reading of the funnel concept is that the entrance to the funnel is where we have come from. Our unsustainable practice must be 'narrowed' as the funnel of growth and development requires change to achieve sustainable life on earth. The unsustainable practice become the boundaries of the funnel, and as we work towards those goals or 'visions' we reflect our planning off the sides of the funnel and continue to strive for a direct pathway to sustainability.

The FSSD teaches that decision-makers should 'back-caste' (Dreborg, 1996) (Robinson, 1990) from the vision that is agreed. The concept suggest forecasting creates a path-dependency. When decision-makers are not fully aware of the requirements to achieve sustainable practice, the forecasted pathway can often lead to further - and costly - unsustainable change. Back-casting from the agreed vision allows for decisions to be adjusted accordingly in efforts toward sustainable practice. As each decision that is unsustainable rebounds off the sides of the funnel the decisions can be improved as required - toward the vision aligned with sustainability principles.

The third component of the FSSD that is relevant to this article is the principle based definition of sustainability (Missimer, Robert \& Broman, 2017) that the group of researchers have established. Definitions of sustainability are not easy to develop and as such there are few available and none within an agreed international legal framework. The definition provided by the FSSD is a valuable tool for the analysis of the Kuthambakkam case study, specifically how the case compliments and aligns with current sustainable development strategy and leadership theory.

The FSSD principle based definition of sustainable development provides a thorough and comprehensive set of phrases that allow decision makers to best understand if their decision making pathway is truly sustainable, in relation to all aspects of human-planet interaction and social justice freedoms. The case in Kuthambakkam is a quality example of how such a comprehensive structure is applied in the community. Although Elango did not utilize the FSSD in the decision making process, the principles of sustainable development are completely aligned. While the FSSD tools are most commonly used in the context of wealth creation, they can be applied with poverty eradication methods as effectively. 


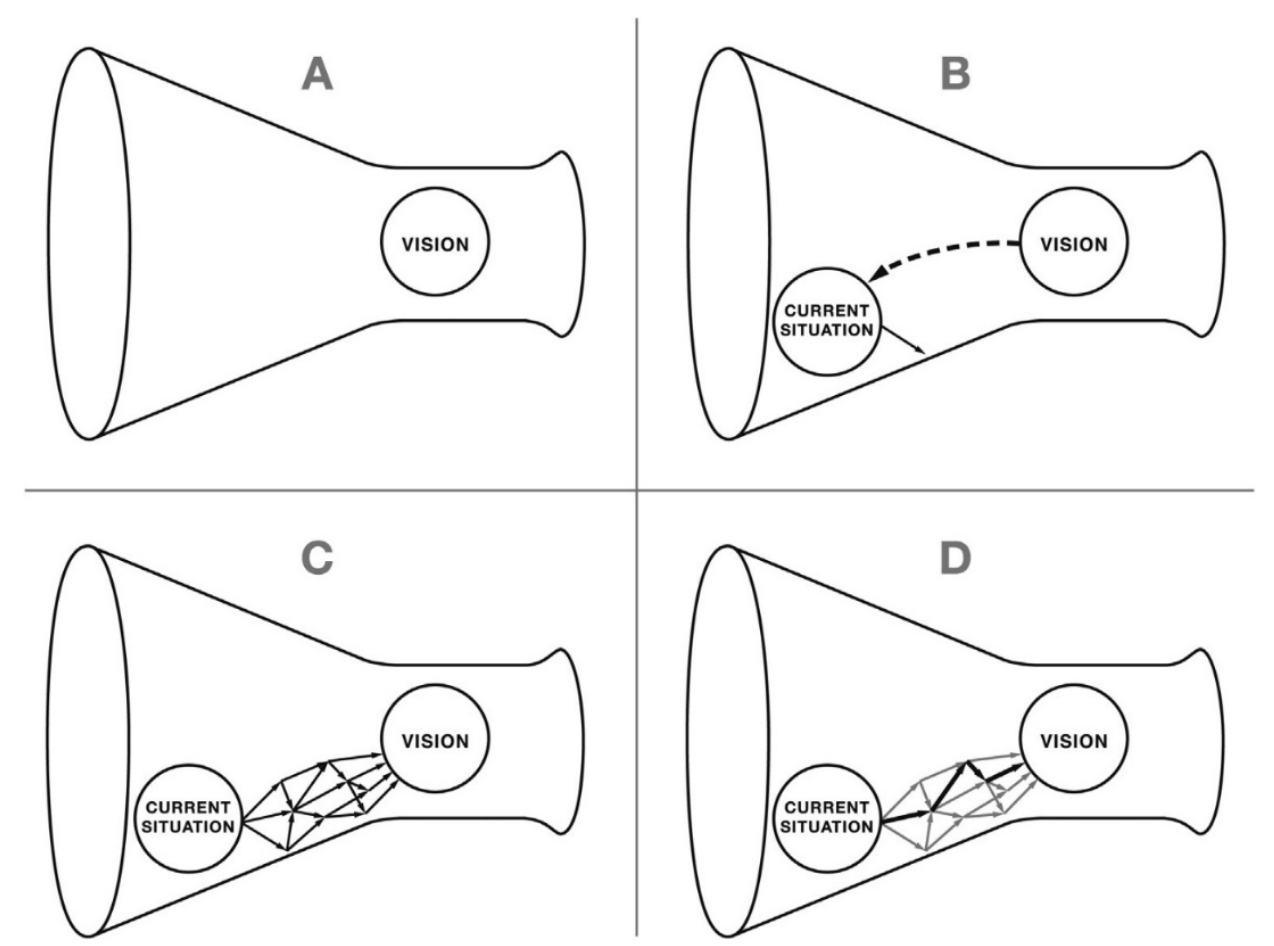

Figure 1. 'The funnel' - framework for strategic sustainable development

(Broman \& Robèrt, 2017)

\section{Kutkambakkam Case through the Framework for Strategic Sustainable Development}

The majority of decisions made in the case of Kuthambakkam are heavily influenced by what would be considered principles that limit structural obligations to human rights in the FSSD. In some cases, the decision making in Kuthambakkam does not fully align with all of the principles of a sustainable society put forward in the FSSD. On occasion, it is necessary for trade-offs between human development and environmental sustainability - particularly where the need to eradicate poverty is limited by the unaffordable cost of environmentally sustainable materials. "If one knows the frame for any vision, various options could be evaluated for their capacity to serve as stepping stones towards a situation where the trade-off dilemma at hand does not exist anymore" (Broman \& Robert, 2017, p20). In the following discussion the FSSD is used to analyse several projects from the range of inter-disciplinary science that is underway through the works of the TVSG. The trade-offs that are required in some cases are shown to be a necessary component of the phase by phase process to sustainable development. Interestingly, the value of each trade-off made in the Kuthambakkam case reflects that which is allocated to the order of the SDGs - with the human requirements for sustainability, a necessary precursor for appropriate environmental management changes.

\subsection{Concrete Slab Sanitation and Housing - The Funnel}

First, 'The Funnel' metaphor is applied in the Kuthambakkam case. Again, Elango does not utilise this specific metaphor, he has plenty in the tool-set for decision making - the point of this is to show how the current theories of sustainable development leadership benefit by understanding cases of successful 'bottom-up' development. To discuss a specific project of the many that are underway in the village of Kuthambakkam - Elango is very willing to share the specifics of the phases of development, the how and why of the decisions that were made. Nothing that is engineered in the TVSG workshop is by chance, or done without appropriate deliberation of the available options. It can most certainly be said that - at times - the decision is not based on environmental sustainability as the key priority. Although all efforts are directed towards a long-term goal of sustainable living, at times, steps towards that goal are impacted by cost-effectiveness and availability of resources.

The housing project that is delivered by the TVSG is an example of how the current solution is not completely aligned with principles of environmental sustainability. Housing and toilet facilities are constructed from panels that are put together using a light gauge steel frame covered in a layer of concrete. The decision to use such materials was not made without deep consideration for a more sustainable option. The reality is, for the residents 
of Kuthambakkam, panels made from some form of organic concrete substitute are not affordable. The technology for such material is available, but for the cost of the traditional concrete, they would not get a suitable alternative from renewable materials. For the village folk, they could not care a less what material is used for construction, they would prefer not to live in mud brick housing with dirt floors and thatched roofs.

Decision makers are aware of the environmental issues caused by use of standard concrete. But the decision was that the immediate improvement to housing was of greater value to the long-term vision of a sustainable village than the impact of continued use of concrete. When an alternative option made from sustainable materials becomes accessible, they will convert to using such material to build homes and toilets. This is the trade-off between addressing poverty in the immediate, and long-term environmental sustainability. The construction methods are already effective and affordable, and with sustainable material use, it is a complete and outstanding model of sustainable housing.

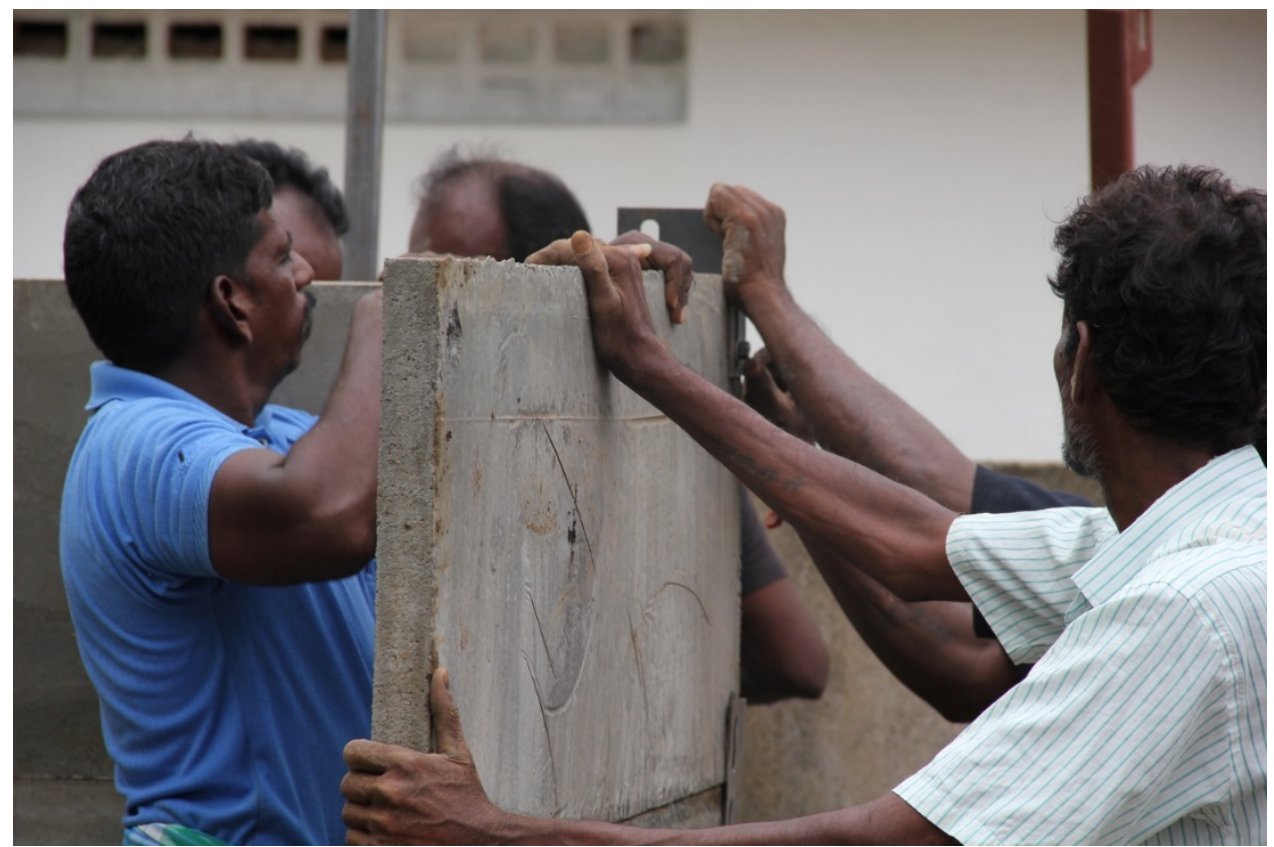

Figure 2. Concrete slab sanitation under construction

Kuthambakkam

\subsection{Electric Bike - Back-Casting from the Vision}

Next the FSSD back-casting and vision concept is used to understand the decision-making process around the TVSG transport solution for Kuthambakkam. The e-bike project is still in the development phase, but things are well progressed. The prototype vehicles are functional and the cost-effectiveness, even with small production numbers, is already suitable for village economics.

Elango and his team had a vision of a sustainable and affordable transport for village residents. Elango is a vocal detractor of the modern drive for petrol motor vehicles in village life. He argues that not only does the cost of petrol place greater burden on struggling families, but the desire for vehicles and availability of loans creates further and unnecessary financial pressure. Added to this, it is often young women who suffer most from lack of transport - this is a structural barrier to their development through education and employment. As one would imagine, the vision created by an existing company whom produce petrol vehicles, and now want to produce electronic vehicles, would be quite different from the vision of e-bikes in Kuthambakkam.

The TVSG has procured a great number of old and disused bicycles. Although many are old, heavy and more cumbersome as push-vehicles, this contributes to their capacity as an e-bike. The decision-making around the engineering of the e-bike components is an excellent example of having a vision of a sustainable solution and back-casting to create a pathway toward the vision. The motor that was chosen, the battery size, breaking system and all the requirements were decided upon for their cost-effectiveness and practicality from a village resident perspective. There is not profit-making on the agenda, it is all about creating a real solution for village residents as an alternative to the petrol motor trap. 
The e-bike cannot compete with the top-speed and distance of the petrol motors. But in the village, this is not an essential requirement for effective transport. The e-bike is designed for use that is the standard requirement of any vehicle in the village. The design can carry a person for around 40 mins to an hour with no pedalling. A top-speed of $18-27 \mathrm{~km} / \mathrm{h}$. There is even a design for a portable solar panel that can be connected during the day to boost the battery for the return journey. Everything is envisioned to minimise the cost while maximising the practical application of the product. Varied options for the e-bike were trialled - those that did not make it could be seen as pathways that reflected off the sides of the funnel. The vision was set, the general concept of the vehicle was established, and the engineering of the end product was done so with sustainability, affordability and freedom as the key factors. This represents an alternative and important example of how the vision and back-casting methods can be applied in the community context. A sustainable society cannot be decided upon by profit-making ideology - solutions will come from within groups aspiring for freedom.

\subsection{Solar Street Lights - Principle Based Definition}

The principle based definition provided by the researchers of the FSSD is a comprehensive tool to guide decisionmaking for sustainable development. In the case of Kuthambakkam, Elango has been working toward his own principles of sustainability for over 25 years. This case shows how these abstract definitions can be worked toward in a comprehensive and holistic manner. Through a systematic, phase by phase process, Elango has addressed a significant amount of barriers to sustainable village life. Each project is guided by an agenda that mirrors with the principle based definition of sustainability - particularly that which relates to human rights. The many projects underway in Kuthambakkam can be evaluated against the FSSD definition for sustainability. In each case you would find that each of the human principles are of significant value in the decision making process, and in some cases, the entirety of the project revolves around a specific human rights issues. For the purpose of this article we will review the community lighting solution developed by Elango and identify how the concept is aligned with the principle based definition of sustainable development.

In this case the product is a standard street light. The key features of the design are affordability, ease of construction, and longevity. The principle that drive the vision - from the FSSD - would be 'people are not subject to structural obstacles to health'. While other principles, such as the structural obstacles to competence would also be relevant in this case - the fundamental principle of the vision is to provide a safer environment for people to live. This is the vision. Features of the end product are designed to work towards other aspects of sustainability, environmental protection for example, but this is not the driving principle. The basic vision is for the street lighting to improve safety for as many villages as possible.

The unit is designed with a light-weight steel pole embedded in a concrete base. The light is run by solar power generated from a panel fixed atop. It can be connected to the grid, as a back-up for when there is not sufficient energy from the sun - which is not so common in India. The unit can be installed with ease by a small crew on any roadside in India. TVSG can produce these street lights for around 7000 - 8000 rupees, around \$100USD per item. The regular streetlights in India are from $40-100$ watts. The TVSG solar street light is only 6 watts. This is sufficient for the safety of the commuters, but a much easier cost to manage - particularly considering the free energy from the sun.

As Elango explains in an interview - the average street light is 40 watts, his light saves 30 watts per day - roughly a kilowatt per unit per month. The average panchayat has around $200-300$ individual street lights. With an energy saving of 1 kilowatt for each light, every month, the benefit of the low-cost and energy efficient street lights are clear and obvious.

Currently there are state government funded operations in several panchayats to install the solar light. The vision is coming to be a reality for thousands of people. While the residents will benefit from the security and safety provided by no longer travelling along dark streets - they will not necessarily pay any heed to the cost saving that such a project entails. They will enjoy the destruction of another obstacle to their health. They will travel more freely to employment and education - enabling economic development. The girls and women of the village will not be as a feared to travel about for their own betterment - for gender equality is most certainly a core motivator for Elango to provide a low-cost and energy efficient street light for the villages of India.

This project is based on the vision of having safe and secure transit for village people, after the sun has gone down. In a busy modern India, many village residents must travel for employment, and all must travel to attend tertiary education institutions. Quite often, these occupations and the subsequent journeys home do not conclude before the sun is set. Therefore, many people are travelling along dark roads in the evenings and into the night. If you can imagine an intersection of dirt roads, often muddied and thick with patches of overuse, people travelling via varied modes of transport, cars, buses, motorcycles, bicycles and on foot. With no street lighting, the risk of accident and 
injury is significant. Young women seeking to achieve economic independence are at most risk. It is no coincidence, and no political stunt, that one of the first solar light construction projects was undertaken at a Muslim girls school to resolve poor lighting on the main entranceway.

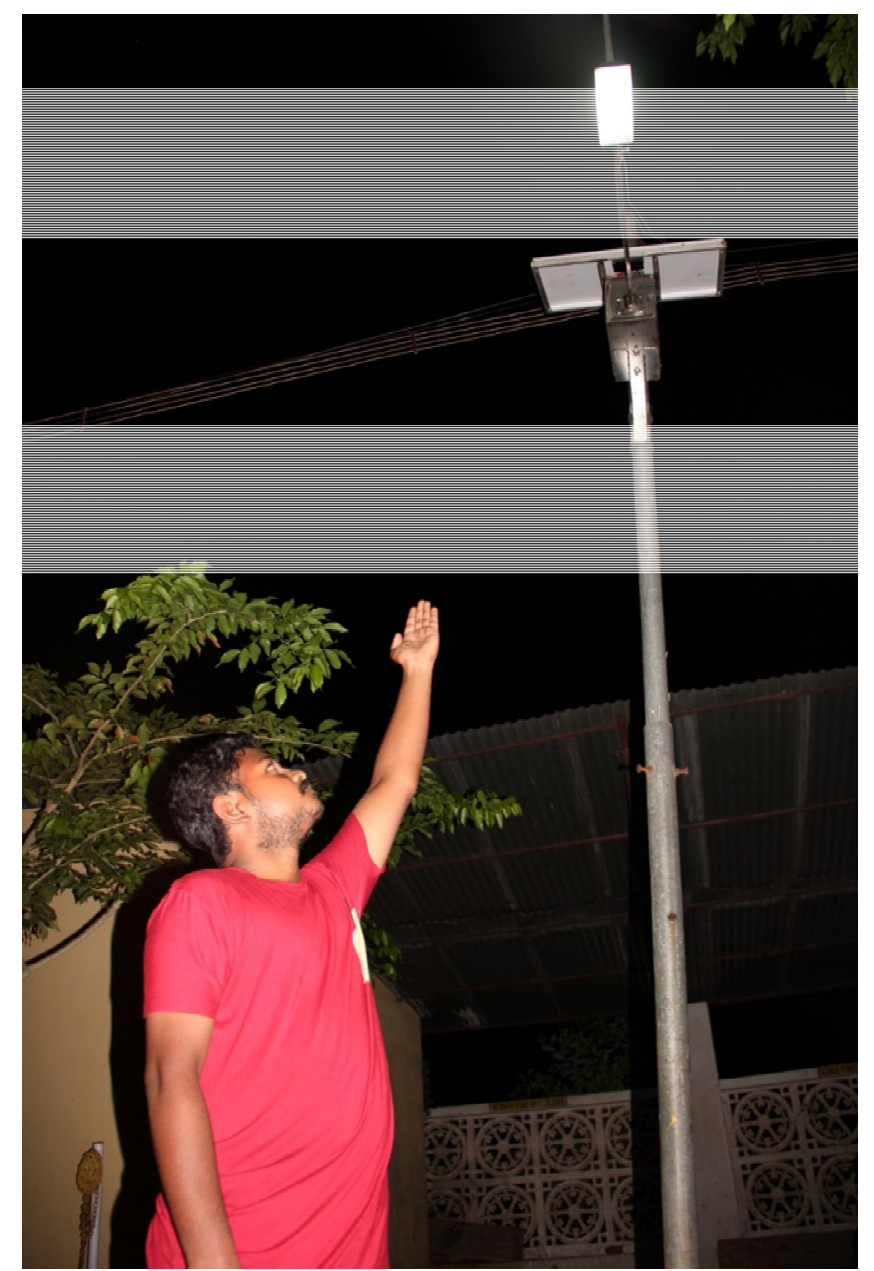

Figure 3. Solar light installed at Muslim Girl's School in Tamil Nadu

The vision is created, based on principles that lead to sustainable development. These examples are used to show how the process outlined by the Framework for Strategic Sustainable Development is well underway in Kuthambakkam and through Elango's leadership. To achieve sustainability across all industries, nations and communities, leaders must learn from the cases of strategic sustainable development that exist in the real world. The Kuthambakkam case allows us insight into the way decision-making tools for sustainability leadership are applied from the bottom-up. It is a matter of understanding that any tools for sustainability leadership can be analysed through the lens of marginalised communities. Through this process, a more robust and effective method of decision making can be developed.

\subsection{Other Cases of Strategic Sustainable Development in Practice}

Through the 25 years that the FSSD has been under development - the researchers have partnered with corporate and government leaders to create practical examples. Several examples will be used to show how the process for corporates continues to be a strive for increased profits. Others who have utilised the FSSD more holistically show the value of doing so. These practical examples will be compared and contrasted with the decision-making in Kuthambakkam to identify the gaps and establish improvements that can be made to sustainability leaders decision-making process.

The Framework for Strategic Sustainable Development was first picked up as a tool for leaders in major corporates in Sweden. Companies with the infrastructure to support such efforts - IKEA, Electrolux, (Broman, 2000) Swedish McDonald's, Scandic Hotels - were the first to dip their toes into the strategic approach to sustainability. The 
pioneers of the FSSD acknowledge that "the FSSD typically serves as an eye-opener and door-opener to executives and other leaders" (Broman \& Robert, 2017, p25). Of the many examples of FSSD in practice that do exist, very few have a longstanding record to review, or a comprehensive approach to implementing the FSSD into actions. Many leaders take an ad-hoc approach to addressing sustainability.

\subsubsection{Consolidate Materials - Electrolux - Aura Light - Interface}

A common application of the FSSD in the corporate sector is to adjust the materials that are used in production to become more sustainable. Companies that have changed the way they construct their products - using the FSSD as a tool - show how the corporate sector goes about this process. Electrolux, Aura Light and InterfaceFlor are three examples where a company has used the FSSD to improve the sustainability of their product materials.

Electrolux utilised the FSSD in their efforts to address the ongoing use of ozone depleting chlorofluorocarbons (CFCs) in the manufacture of household cooling appliances. The company went through a process of identifying alternatives with a short-term value, then excluding as options due to their long-term unsustainability (Robert \& Broman, 2013). Electrolux CEO Leif Johansson was quoted in October 2006 "It was not until 10 years later that we fully realised how much money we had saved and earned from applying the FSSD to our business" (Robert \& Broman, 2013, p5).

The case of Aura Light shows an approach to managing products sustainability from a corporate profit-focused perspective. "Aura Light is exploring new business models built on Light as a Service, where the ownership of the physical products remains with Aura Light, to facilitate control of the materials" (Broman \& Robert, 2017, p25). Their solution is to manage the products through in-house upgrades. Where the company maintains ownership of products and they are 'leased' and therefore able to upgrade within the business model.

Interface was the first international company to adopt the FSSD as a tool for sustainability leadership. Their strategy to improve the sustainability of the flooring cover industry was to improve their manufacture and installation of the carpet tiles they produce. "With a closed loop materials management and a reduction of waste generated, a substitution to polymers produced from renewable sources of carbon was affordable" (Lindahl, Robert \& Broman, 2014, p101). Interface have introduced a more comprehensive approach than many of the other cases of FSSD in practice. Their CEO Ray Anderson was quoted in October 2007 "we are doing better than ever on bottom line businesses. This is not at the cost of social or ecological systems, but at the cost of our competitors who still haven't got it" (Broman \& Robert, 2017, p25).

There is a clear comparison between these examples, and to the projects in Kuthambakkam that are used in this study. A major difference is that in each of the corporate examples, there was no effort made to improve access to the products by at-need groups. The design changes were purely based on improving the sustainability of the materials involved. As this design change was occurring, there could also have been efforts made to create products that would meet the needs of disadvantaged communities. Refrigeration and climate control from Electrolux that was designed for sustainability and for access by low-income communities. Lighting management or flooring solutions that meet the needs of disadvantaged peoples, not only improve the sustainability of the construction materials.

\subsubsection{Community Based Case Studies}

Two case studies of the FSSD in use for community orientated leadership are provided here as a comparison to the process in Kuthambakkam. The first is the Canadian municipality of Whistler, which used the FSSD to guide a solution to the heating required for the hosting of the Winter Olympics (Gordon, 2004). Additionally, the FSSD research team were involved in a study to identify a strategic approach to sustainable transport in Sweden (Robert, Boren, Broman, 2016).

In the case of Whistler, the FSSD was used to identify that a large gas pipeline to meet the energy needs of the area was not sustainable. The agreed alternative was to build a smaller pipeline, to meet the need in the short-term, while continuing to work toward a geothermal energy solution that was far more sustainable going forward. This shows how the community sector can use the FSSD as a tool, but this lacks the holistic approach that is on display in Kuthambakkam. For example, the First Nations traditional owners of the land where Whistler is based would inevitably have a more complex and integrated approach to this issue. The contribution of the First Nations members of the community is not known, but it is clear that their well-being was not the driving force of the decision making process.

The research project to design a strategic approach to sustainable transport system was focused on the Swedish Government's established goal of a 'fossil-free transport system in Sweden by 2030' (Ministry of the Environment, 2014). This is perhaps the most comprehensive application of the FSSD in a community-based or corporate context. 
There is a two-part journal article publication that provides a complete summary of the process (Robert, Boren \& Broman, 2016) (Boren, et al, 2017). In terms of a comparison to the holistic sustainable development decisionmaking in Kuthambakkam, this case gives the closest example that can be compared. The difference is, in the case of a sustainable transport solution in southeast Sweden, the planning and decision-making is still in the theoretical stage. In the case of Kuthambakkam, this comprehensive and holistic approach is on display with a vide variety of practical examples for over two decades.

"The principles of sustainability leadership respond to the challenges of an increasingly complex world. Grounded in emerging social science research, they are informed by complexity science models and they offer a powerful view of leadership and human dynamics that could trigger a transformational shift in how we see and function in the world.. Leaders who adopt this expanded view can engage others using different assumptions about how people interact to create meaningful change" (Ferdig, 2007, p27).

\section{The Case Study - COVID-19 Solar Disinfectant}

\subsection{Solar Powered Production of Sodium Hypochlorite (HYPO)}

Sodium Hypochlorite - commonly known as Chlorine-Bleach is a compound that plays an important role in the war against germs. It is a very useful and an inexpensive disinfectant. From the use of Sodium Hypochlorite (HYPO) to purify water to the disinfection of surfaces, the areas of application of this compound are vast.

As the world continues to fight against the Covid19 pandemic, the use of disinfectants globally has risen by many folds. While people are educating themselves on the importance of disinfecting their surroundings, there exists a vast majority of people in rural India who are still learning about this pandemic and are unable to respond to the situation as their knowledge and capability to claim the use of these disinfectants is limited. Many remote rural villages find it challenging to access disinfectants for their domestic needs owing to reasons of lack of knowledge on the use of disinfectants and economic constraints of not being able to afford one from the market.

Elango has built the solar powered production of Sodium Hypochlorite with the motive to meet the sanitation and disinfection needs of the village. Communities can learn and use this technique to produce disinfectants and other sanitary products locally and ensure full local sanitation (Kothari, 2020). Additionally, the production process achieves empowerment, affordability and is focused on well-being for the most disadvantaged. This project has received the focus of $\mathrm{BBC}$ journalists - due to it's importance in the current health pandemic (BBC, 2020).

The existing systems in the production of Sodium Hypochlorite follows two possible ways, first method is passing chlorine gas in sodium hydroxide which is practiced by chloro-alkali industries, where they concentrate the solution and even get the crystalline powder of HYPO. For disinfection purpose, this salt is again diluted to 0.5 to 1.0 percent solution.

The second method of simply electrolysing the common salt (sodium chloride) dissolved in lower concentrations like 4 to 5 percentage solution in an electrolyte by passing a DC current in controlled conditions. In this process people use AC to DC rectifiers and draw the grid current from the electrical line. Hence the grid current is a key requirement along with common salt.

The model incorporates the use of solar panels as a source of electricity. For producing one litre of $1 \%$ sodium hypochlorite solution 60 watts of power is drawn from the solar panel. This is equivalent to burning of 50 grams of coal which in turn emits 1500 litres of $\mathrm{CO} 2$ gas to the atmosphere. Right now he has modelled a 25 litres and 200 litres per day production. In the scale of 25 litres of per day system the $\mathrm{CO} 2$ emission would be about 37500 litres and this emission is saved here. For the larger unit of 210 litres per day system the saving of $\mathrm{CO} 2$ emission is $37500 \times 8=300000$ litres of $\mathrm{CO} 2$ per day. This proves to be a great contribution of green to the future generation. It works at 12 volts DC and the potential risk of electrocution is almost absent. Since water and salt are the basic raw materials used in the process, there are no harmful/hazardous by-products from the operation unlike other chemicals and disinfectants.

The motivation and decision to build this model was based on the idea of self-reliance, creating employment for a group of people and taking care of the needs of the sanitation and disinfection of the village amidst COVID-19 pandemic. The main raw materials are salt and water which are low in capital cost and easily accessible. The production and distribution involves training a small group of people responsible for one system in one locality. As and when similar working units are built at various localities, groups of people from that particular locality will be trained for production and distribution. An entire village meeting its own public and personal satiation and disinfectant needs during critical times will be a guiding light to the entire nation.

The entire process is decentralized and to be set in more such places with a motive of creating opportunities to disadvantaged people in accessing disinfectants at a very low cost and spreading awareness on the same, all of 
which is ultimately contributing towards self-sustainability and sustainable development.

Sanitation, self-reliance, sustainability, cost effectiveness were the major driving factors behind the development of this model.

For the production of 25 litres of $1 \%$ HYPO solution per day the following are the requirements:

1) Battery - one 100 Ampere Hours (AH), 12 Volts

2) Solar panel - one $330 \mathrm{Watts}$ panel (OR) four $100 \mathrm{Watts}$ panel

3) Controller, current gate and an electrolyte

4) Storage tank and an overall standing pillar

The estimated cost for a 25 -liter production/day is estimated approximately at $\$ 950$ (70,000 INR), the cost of production of a 200 -litre production system is approximately $\$ 7500$ (560,000 INR). The requirement of batteries and panels will be eight times that of the 25 -litre production.

Seven units of the 25 Litre production system have been installed in and around kuthambakkam and are successfully functioning. Each unit has been run by women from the local community through self-help groups, creating job opportunities and serving as a source of income during these tough times where people have been losing jobs and facing salary cuts.

One 200-litre production system has been installed in the neighbouring town of Thirumazhisai vegetable market which houses 200 vegetable and fruit shops. People from the neighbouring villages and also people from the city of Chennai - the capital city of Tamil Nadu state, travel to this vegetable market to get fresh fruits and vegetables. The major area of application in the vegetable market is disinfecting the public area where many people are gathered to buy their vegetables and fruits. The nearby hospitals and public access buildings are being disinfected using sodium hypochlorite produced and dilated from this system.

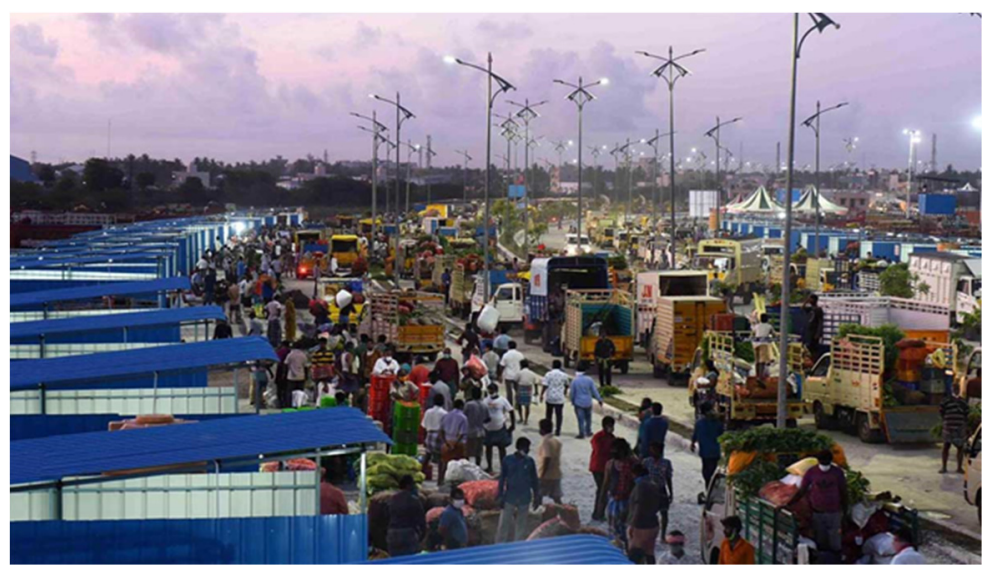

Figure 4. Thurimazhisai vegetable market where HYPO is being used (Subbian, 2020)

In villages and smaller hamlets, its mostly the 25 litres production system, and the generated sodium hypochlorite has been successfully used for disinfecting places, for mopping floors and cleaning public toilets.

Self-Employed Women's Association (SEWA), a trade union from the neighbouring state of Kerela, has expressed interest in learning about the system, for installing it in various rural areas to mitigate the spread and also create employment opportunities to regain some sort of economic stability among the disadvantaged people. This innovation has been covered by various media - newspaper articles, magazines, social media platforms, news channels for creating awareness on the system's simplicity in construction and working as a source of employment and a tool for mitigating the spread of the virus, so that it can be adopted throughout India. 


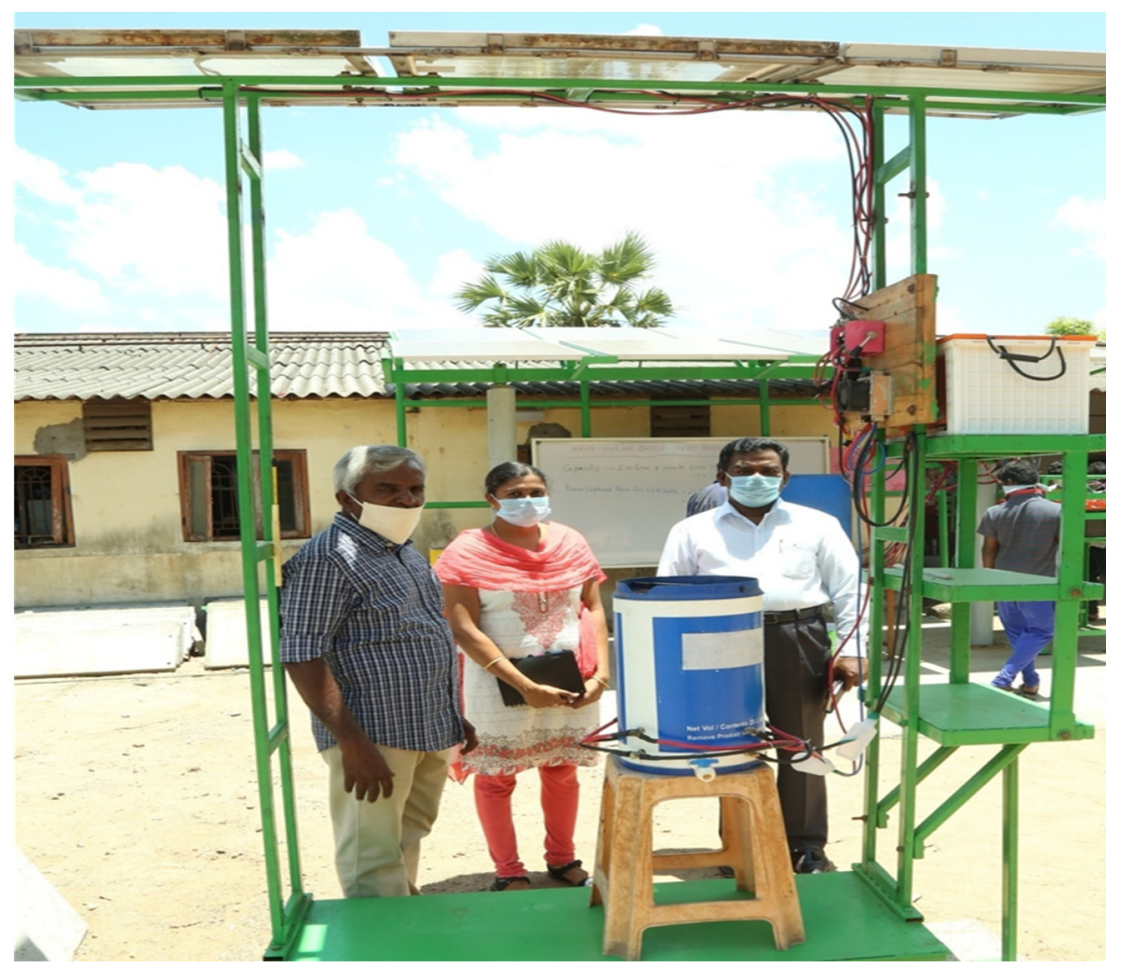

Figure 5. 25 liters of $8000 \mathrm{NaOCl}$ ppm solution per day production unit

\section{Applications:}

1) For strong liquid waste- 5 to 10 times the dilution is required

2) Drains, Toilet floors and basins 15 to 20 times of dilution is required

3) House floors, hospital floors and clothes of sick people- 20 to 30 time of dilution is required

4) Cleaning and wiping household items- 50 times dilution is required

5) Disinfecting drinking water 2 drops for every 6 liters of water is required

One 25-liter system can cater 200 families. One or two units per village can meet the entire village's requirement. In terms of its installation beyond rural areas this model can also be implemented in apartments, universities, hospitals and other public areas, catering to the needs of disinfecting and also making them self-sustaining. One 25 -liter system can cater 80 to 100 families. For cleaning the environment by spraying the surrounding including the drains and for distributing $1 / 2$ litre of 2000 ppm solution to every family and the other supporting staffs.

For larger hospitals and institutions a 100 litre or 200 litre systems will meet the requirements. In cities, for every 1000 families one 100 litres' production unit will cater the needs. The activity is geared up for installing more units across the country. 


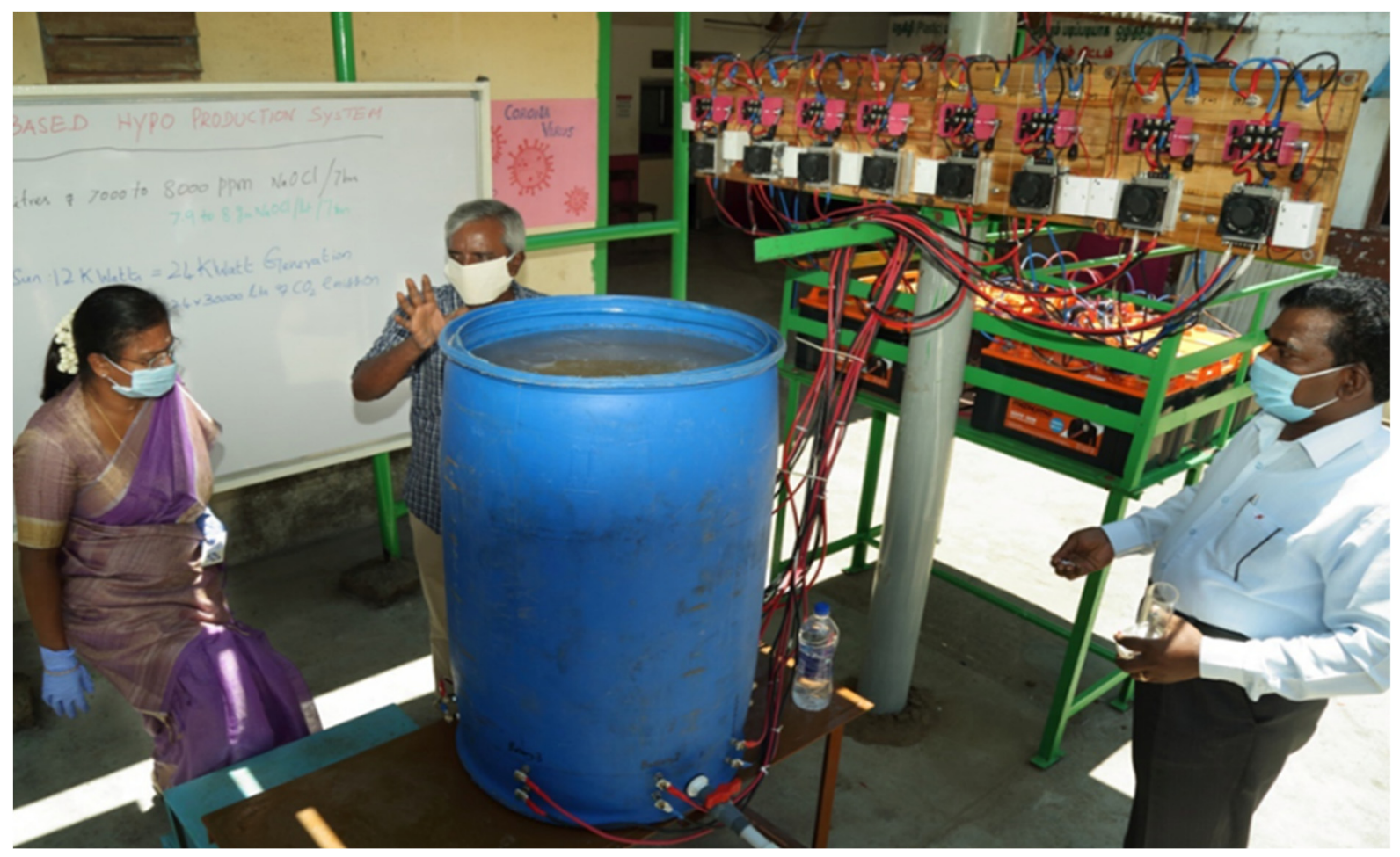

Figure 6. 200 Liters production unit

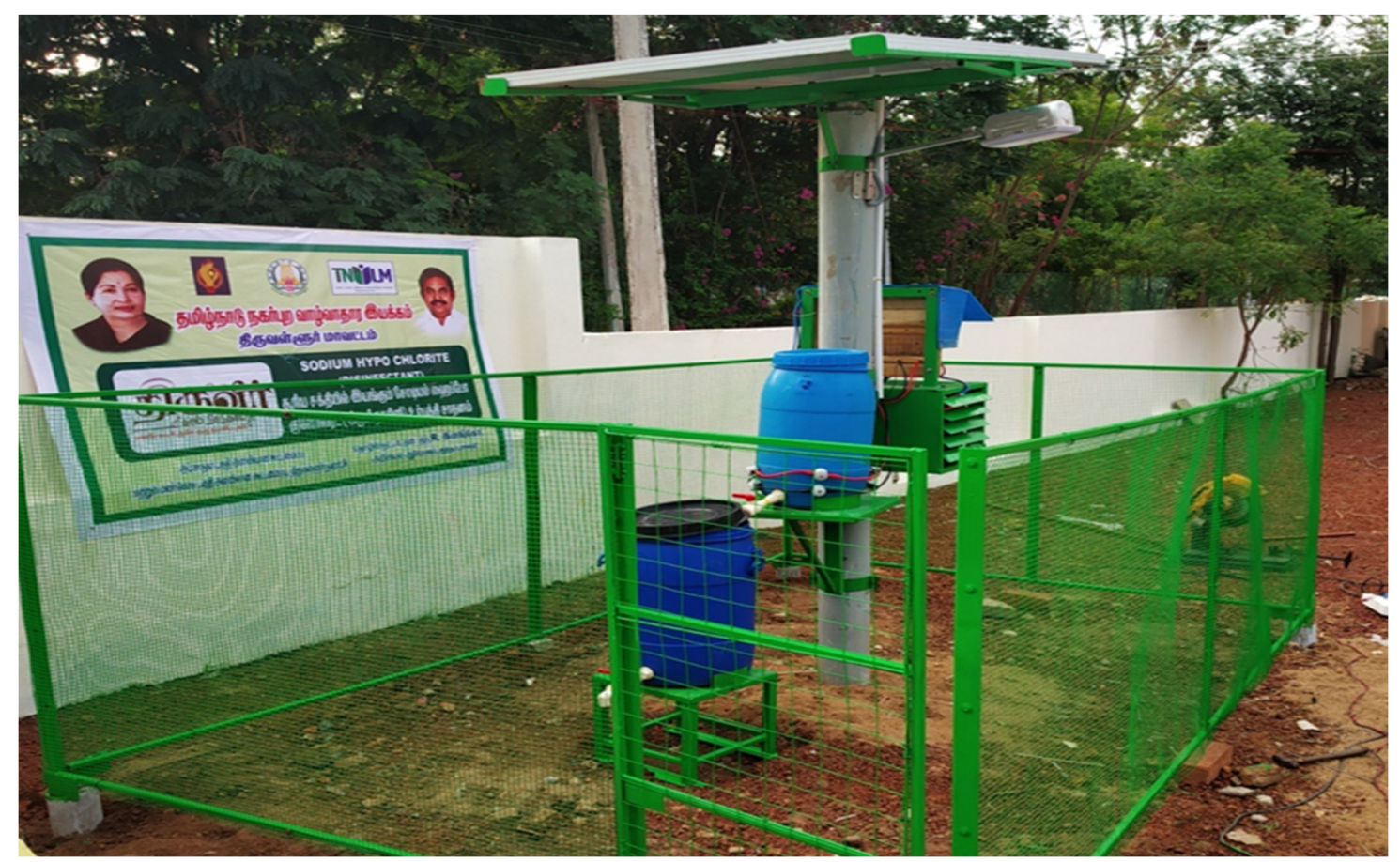

Figure 7. 25 Liters production unit installed in a locality at Thiruvallur, a neighboring village to Kuthambakkam

\subsection{Solar HYPO \& Framework for Strategic Sustainable Development}

When the solar-HYPO project is analysed for it's decision making process - using the Framework for Strategic Sustainable Development as an analytical tool - what does it reveal? What can be drawn from this process to advise and guide leadership for sustainability?

It is clear that well-being is the key goal of the solar HYPO project - or well-being is the outlet of the funnel. 
Elango clarifies that the goal is for people in the villages to have capacity for protecting themselves via sanitizing and disinfecting their living and workplaces - providing employment for a group of people, and creating a sense of self-reliance while doing so. This is the vision from which is being back-casted to develop a product that is appropriate to meet this need. From the outset, the decision making is based on achieving this - not simply having a way to safely clean and protect from the COVID-19 pandemic - but to improve well-being while doing so. "In strategic planning, one should distinguish the definition of the goal of the planning and the process by which it is approached" (Broman \& Robert, 2017, p19).

In a regular corporate decision making context the desired outcome of a product design would be one that has a low-cost for production, high profit margin and with appropriate leadership, the sustainability of the product would also be a factor. Corporate decision making process is not designed to factor in the well-being of a disadvantaged group. That is not to say that this needs to be the case, the point of this article is to encourage sustainability leadership in corporate and developed world to realise that considering the needs of the most disadvantaged can actually lead to better decisions and thus sustainable profits.

\subsubsection{Solar HYPO \& The Funnel}

The FSSD is designed as a tool to assist leaders to make decisions that are more sustainably minded. The use of the funnel is a metaphor to encourage decision makers toward sustainability targets, rather than purely profit based goals. Elango is following a similar process to find sustainable solutions to the problems faced in his community - with a particular focus on the difficulties faced by the most deprived. The way the funnel is applied in this context is to prioritise the well-being of disadvantaged members of society as a key outcome of the decision-making process. The options that do not lead to this outcome reflect off the edges of the funnel and are adjusted to ensure the end result meets the key goal of well-being for disadvantaged peoples. This is why the process of producing the solar HYPO can be learnt by, and adapted to any rural village in India - or other developing world environments. The specific scientific method used to create the disinfectant, the choice of materials for production and the decentralised nature of the production process are all established in such a way to achieve the end goal of wellbeing for the people. All other options and possibilities that were considered did not have such a linear path to the opening of the funnel. It is quite likely that the decision process could have been as accessible to the community but much more profitable for the engineers. This shows how the funnel concept is applied in a decision making process that established well-being of disadvantaged as a goal. Obviously not all leaders for sustainability can consider well-being as the key outcome, but most certainly anyone working in corporate or government institution leadership for sustainability can improve their consideration of these factors in their own funnel - with cases such as Kuthambakkam as an example of how one might do so.

\subsubsection{Solar HYPO \& The Vision}

In the process of the FSSD - clearly the vision from which is being back-casted is the key element to guide the decision-making paradigm. In the case of Kuthambakkam - sustainable development and eradication of poverty are inevitably intertwined. The address of global poverty is the first of the United Nation's Sustainable Development Goals as it is a significant barrier to other forms of development (Liu, Yu \& Wang, 2015) (Roy, et al, 2018). When the first Kuthambakkam panchayat local government was established the first call of business was the break-down of the illegal alcohol brewing dependency. The vision has not changed since this time. "Backcasting begins by defining the vision, and then asks: what shall we do today and subsequently to get there?" (Broman \& Roberts, 2015, p19) (Dreborg, 1996)

The vision in the case of Kuthambakkam decision making is to improve the overall well-being of the population - particularly in regards to the most disadvantaged and marginalised members of society. The wealthier members of Kuthambakkam can afford their own disinfectant. They may also choose to purchase, and benefit from the solar HYPO disinfectant production - but the vision that guided design of the product is not created with their needs in mind. The vision has been the same since the outset of the development process in Kuthambakkam. It is the decisions about 'what shall we do today to get there?' that are responsive to the most pressing and current issues at hand. This is part of the reason why the solar HYPO was established so quickly - in response to the COVID-19 pandemic. While the TVSG has never before been faced with the challenge of producing a low-cost and low-risk disinfectant, they have many times before considered how to address problems that deter from sustainable development in the village. The commonality is that for each of these problems, the decision-making to provide a solution is based in the same overall vision - which is in turn guided by the same basic principles that achieve well-being. With the solar HYPO project, this practiced ability to avoid path dependency by back-casting from a vision of well-being results in a product that meets many of the requirements for sustainability. Not only the important hygiene and health related goals, but others that are well aligned with the principles based definition of 
sustainability.

The decision-making process in the solar HYPO project is well aligned with all of the principles in the definition of sustainability included in the FSSD. For the disinfectant production decision making, there were no trade-offs between the principles required to come to the end product. In other projects that the TVSG works on, trade-offs are in play but in the case of solar HYPO - it is well aligned with the environmental and social principles.

\subsubsection{Solar HYPO \& The Principle Based Definition}

The production model designed by Elango for HYPO uses simple organic chemicals - water and salt - which can be obtained sustainably. The energy required for production is generated through solar power and therefore requires no fossil fuel. As the materials are organic and the process is non-toxic, there are no hazardous by-products. This is in alignment with the principles of not systematically increasing the "concentrations of substances extracted from the Earth's crust" "concentration of substances produced by society" or "degradation by physical means". The solar HYPO decision-making does not contravene the environmental principles of the FSSD.

The decision making in the solar HYPO project breaks down structural obstacles to health and competence in particular. In no way do the decisions subject people to structural obstacles to the other principles of influence, impartiality, or meaning-making - in fact it could be argued that the solar HYPO decision making process also works to limit these structural obstacles also. For the purpose of this article - it is relevant to point out how this project is focused on breaking down obstacles to health and competence.

Most apparently, the health of the most disadvantaged members of the community is the priority of this project. The target market is those who cannot afford to purchase appropriate disinfectants to maintain hygiene standards required during the increased risk from COVID-19. The low-cost of the materials - and the cost free operation once the equipment is in place - means that the product will be the lowest cost possible for the community. Not having access to simple disinfectant during this high-risk period would "systematically undermine their possibilities to avoid illness" (Broman \& Roberts, 2017, p p23). By developing this solution, Elango's solar HYPO project make a significant contribution to disadvantaged communities' ability to overcome this structural obstacle to their health needs.

The additional obstacle that is addressed in a forward and constructive decision is to create the product with a decentralised manufacture method. The information provided here clearly outlines how the manufacturing apparatus can be easily constructed in any rural and resource poor location. The training required to operate the system is minimal and easily taught to willing participants. By giving the community capacity to produce their own disinfectant, and training local people in the operation of the production process - this empowers the people and provides them with transferrable skills. This is a clear effort to address the principle of not subjecting people to structural obstacles to competence.

By analysing the decision making process that led to the end result of the solar HYPO project - using the concept of the funnel, the back-casting from the vision, and the principle based definition of the FSSD - one can see the value for sustainability leadership theory. Of the many options that could have been decided upon to create a sustainable solution to the crisis of sanitation in Indian villages during the worst health pandemic in over a century - this solar HYPO project resulted the way it did, based on the vision of the leader. What is important to note is that this was the solution to this current problem - there will be other problems of equal or greater proportion in the coming decades - hopefully not related to health pandemics, most certainly related to environmental disasters and access to resources, mostly water. The fact that the decision making to meet the COVID-19 challenge resulted in the solar HYPO project - reflects the experience and knowledge of a practitioner of sustainability leadership, with over a quarter century experience in a developing world context. It is no accident that the solution to a disinfectant for Indian villagers in response to COVID-19 fares so well when analysed using the FSSD - it is the culmination of many decisions across an inter-disciplinary framework required to achieve sustainable development in marginalised and disadvantaged communities.

\section{Conclusion}

When the decision making in Kuthambakkam is compared to the other examples of the FSSD in practice - what is found is that the decision-making process in Kuthambakkam leads to outcomes that have far-reaching benefits. The product itself is designed with deep consideration of sustainability principles. With well-being as the goal there are significant benefits for marginalised and disadvantaged communities that are difficult to quantify, but very easy to understand. When sustainability leaders focus on empowerment, horizontal growth and improving well-being, the outcomes have far greater potential for true sustainability.

The case of Kuthambakkam viewed through the FSSD provides opportunity to look at how a real world example 
of sustainable development in a marginalised community appear through tools that are designed for developed world scenarios. The point is that it is possible to analyse other successful cases of sustainable development specifically from within marginalised communities that establish locally-governed solutions - using tools designed for sustainability leaders of the developed world. Marginalised community leaders are pioneering sustainability solutions that have significant application in any community or marketplace. Doctrines such as 'simple solutions to complex problems' or 'decentralised production' are exemplified in these real-world scenarios. These provide bodies of evidence to show what steps can be taken to achieve more sustainable outcomes. Those working towards sustainable solutions in corporations or wealthy communities can more easily understand the successful cases of sustainable development in marginalised communities when the results are analysed using tools that are designed for their world.

Future studies in this field, and with the case of Kuthambakkam could involve the mapping of a product design and manufacture, including the timeline of all the materials involved. There is much to be understood from the way that well-being was achieved in the village. Studies to show that the well-being has in fact occurred, and to connect the well-being improvements to a tangible factor are very important in efforts to address poverty.

Those who are looking to improve skills for sustainability leadership - be that in the corporate or government sector - have much to gain by witnessing the results in Kuthambakkam, and other cases of successful bottom-up, strategic sustainable development. It is essential that such outstanding models are studied and nurtured. Cases where the well-being of the most disadvantaged is the priority show what is possible when morals, ethics and compassion take the mantle of profit, growth and wealth. 


\section{Appendix A. Principle-based definition of sustainable development (Broman \& Robert 2017)}

Appendix A: The chart shows relations between various entities related to a principled definition of sustainability. The arrows have the following meaning: what is in the box at the tail of the arrow (if true/fulfilled) makes what is in the box at the head of the arrow possible/true/fulfilled.

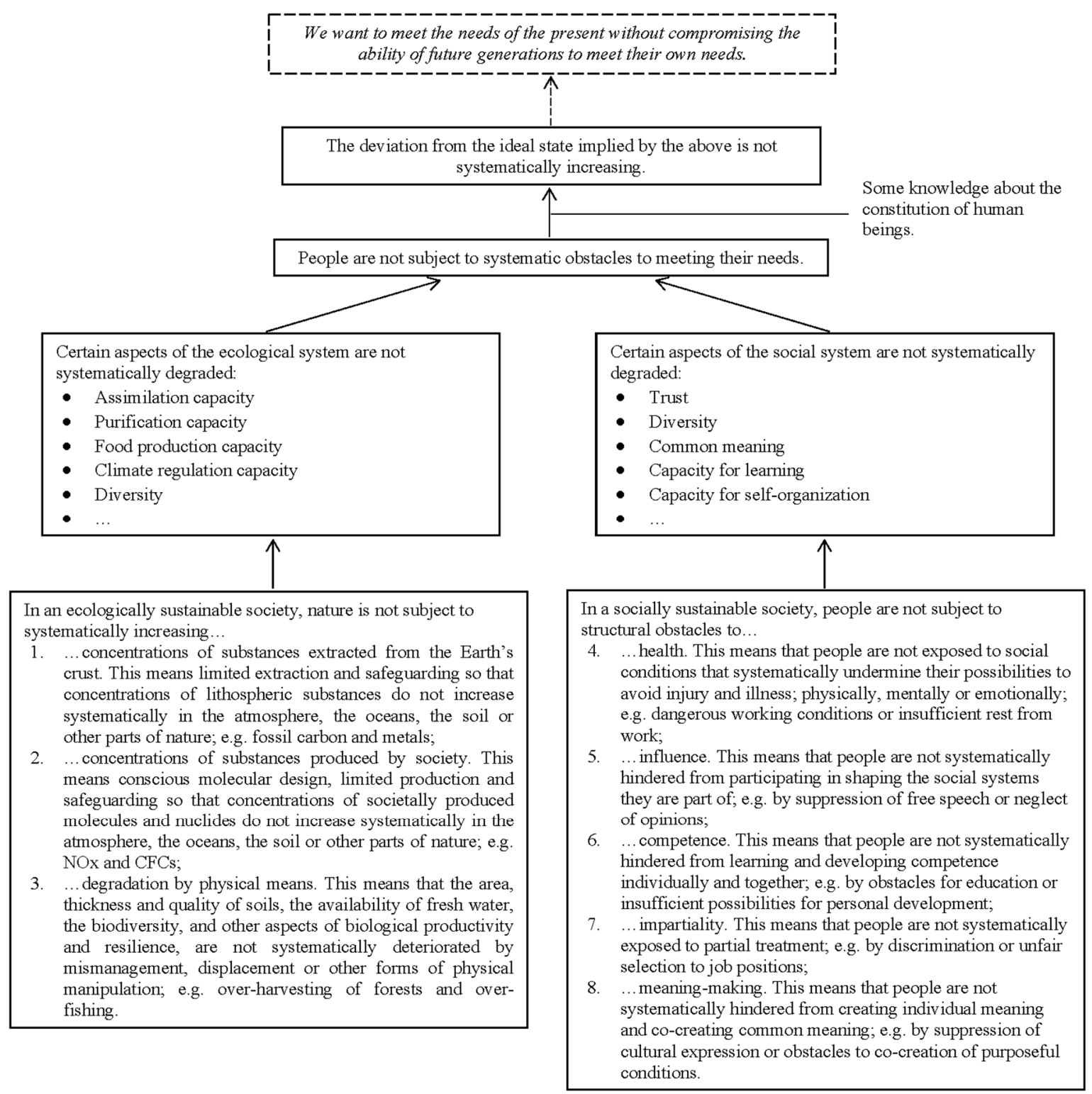

\section{References}

Anuradha, R., Dutta, R., Raja, J. D., Lawrence, D., Timsi, J., \& Sivaprakasam, P. (2017). Role of Community in Swachh Bharat Mission. Their Knowledge, Attitude and Practices of Sanitary Latrine Usage in Rural Areas, Tamil Nadu. Indian Journal of Community Medicine: Official Publication of Indian Association of Preventive \& Social Medicine, 42(2), 107. https://doi.org/10.4103/0970-0218.205213

Baxter, P., \& Jack, S. (2008). Qualitative Case Study Methodology: Study Design and Implementation for Novice Researchers. The qualitative report, 13(4), 544-59.

BBC - British Broadcasting Commission. (2020). Solar powered disinfectant production machine - Awesome Tamil. Retrieved from https://www.bbc.com/tamil/india-53294210

Beck, S., \& Mahony, M. (2018). The IPCC and the New Map of Science and Politics. Wiley Interdisciplinary Reviews: Climate Change, 9(6), e547. https://doi.org/10.1002/wcc.547 
Borén, S., Nurhadi, L., Ny, H., Robèrt, K. H., Broman, G., \& Trygg, L. (2017). A Strategic Approach to Sustainable Transport System Development-Part 2: The Case of a Vision for Electric Vehicle Systems in Southeast Sweden. Journal of Cleaner Production, 140, 62-71. https://doi.org/10.1016/j.jclepro.2016.02.055

Bottery, M. (2016). Not So Simple: The Threats to Leadership Sustainability. Management in Education, 30(3), 97-101. https://doi.org/10.1177/0892020616653059

Bratt, C., Hallstedt, S., Robèrt, K. H., Broman, G., \& Oldmark, J. (2013). Assessment of Criteria Development for Public Procurement from a Strategic Sustainability Perspective. Journal of Cleaner Production, 52, 309-316. https://doi.org/10.1016/j.jclepro.2013.02.007

Broman, G. I., \& Robèrt, K. H. (2017). A Framework for Strategic Sustainable Development. Journal of Cleaner Production, 140, 17-31. https://doi.org/10.1016/j.jclepro.2015.10.121

Broman, G., Holmberg, J., \& Robèrt, K. H. (2000). Simplicity Without Reduction: Thinking Upstream Towards the Sustainable Society. Interfaces, 30(3), 13-25. https://doi.org/10.1287/inte.30.3.13.11662

Cajka, A., \& Cajka, A. (2014). Kuthambakkam: Laboratory of Village Economics. Pune: Kalpavriksh.

Clarke, J., Heinonen, J., \& Ottelin, J. (2017). Emissions in a Decarbonised Economy? Global Lessons from a Carbon Footprint Analysis of Iceland. Journal of Cleaner Production, 166, 1175-1186. https://doi.org/10.1016/j.jclepro.2017.08.108

Dankelman, I. (Ed.). (2010). Gender and climate change: An introduction. Routledge.

Delina, L. L. (2016). Strategies for Rapid Climate Mitigation: Wartime mobilisation as a model for action? Routledge. https://doi.org/10.4324/9781315627663

Dreborg, K. H. (1996). Essence of Backcasting. Futures, 28(9), 813-828. https://doi. org/10. 1016/S00163287 (96) 00044-4

Ferdig, M. A. (2007). Sustainability Leadership: Co-Creating a Sustainable Future. Journal of Change Management, 7(1), 25-35. https://doi.org/10.1080/14697010701233809

Godinez, G., Victor-Gallardo, L., Angulo-Paniagua, J., Ramos, E., Howells, M., Usher, W., ... \& Quirós-Tortós, J. (2020). How Modelling Tools Can Support Climate Change Policy: The Case of Costa Rica in the Energy Sector.

Gordon, S. (2004). The Natural Step Along Whistler's Journey. Whistler2020, Whistler, British Columbia, Canada. Retrieved from http://www.whistler2020.ca/whistler/site/genericPage.acds?context=1967914\&instanceid=1967915

Gram, V., \& Annexure, I. (n.d.). Rural Housing and Habitat Development: Experience of Gram Vikas, OrissA. https://pdfs.semanticscholar.org/6495/3ea98aa82a04a7c1e5a9f39414aba6538eea.pdf

Hargreaves, A., \& Fink, D. (2003). Sustaining Leadership. Phi delta kappan, 84(9), 693-700. https://doi.org/10.1177/003172170308400910

Hargreaves, A., \& Fink, D. (2004). Sustainable Leadership Matters. Educational Leadership.

Heizmann, H., \& Liu, H. (2018). Becoming Green, Becoming Leaders: Identity Narratives in Sustainability Leadership Development. Management Learning, 49(1), 40-58. https://doi.org/10.1177/1350507617725189

Johnson, K., Hays, C., Center, H., \& Daley, C. (2004). Building Capacity and Sustainable Prevention Innovations: A Sustainability Planning Model. Evaluation and program planning, 27(2), 135-149. https://doi.org/10.1016/j.evalprogplan.2004.01.00

Kennedy, D. (2018). A world of struggle: How power, law, and expertise shape global political economy. Princeton University Press. https://doi.org/10.2307/j.ctt1wf4cz3

Khan, S., Siddique, R., Ali, A., Xue, M., \& Nabi, G. (2020). Novel Coronavirus, Poor Quarantine, and the Risk of Pandemic. Journal of Hospital Infection, 104(4), 449-450. https://doi.org/10.1016/j.jhin.2020.02.002

Kothari, A. (2018). Kuthumbakkam: Re-embedding Economy in Society. Ariel Salleh, Australian political ecologist; author of Ecofeminism as Politics, and editor of Eco-Sufficiency \& Global Justice, 261.

Kothari, A. (2020). Extraordinary Work of Ordinary People. Beyond Pandemics and Lockdowns. Retrieved from http://vikalpsangam.org/article/extraordinary-work-of-ordinary-people-beyond-pandemics-andlockdowns/\#.XzNcMRMzY3g

Kristjansdottir, R., \& Busch, H. (2019). Towards a Neutral North-The Urban Low Carbon Transitions of Akureyri, 
Iceland. Sustainability, 11(7), 2014. https://doi.org/10.3390/su11072014

Lindahl, P., Robèrt, K. H., Ny, H., \& Broman, G. (2014). Strategic Sustainability Considerations in Materials Management. Journal of Cleaner Production, 64, 98-103. https://doi.org/10.1016/j.jclepro.2013.07.015

Liu, Q. Q., Yu, M., \& Wang, X. L. (2015). Poverty Reduction Within the Framework of SDGs and Post-2015 Development Agenda. Advances in Climate Change Research, 6(1), 67-73. https://doi.org/10.1016/j.accre.2015.09.004

Llavador, H., Roemer, J. E., \& Silvestre, J. (2015). Sustainability for a warming planet. Harvard University Press. https://doi.org/10.4159/9780674286597

Masson-Delmotte, V., Zhai, P., Pörtner, H. O., Roberts, D., Skea, J., Shukla, P. R., ... Connors, S. (n.d.). Summary for Policymakers. Global Warming of 1.5 C. An IPCC Special Report on the Impacts of Global Warming of 1.5 C Above pre-Industrial Levels., Global Warming of 1.5 C. An IPCC Special Report on the Impacts of Global Warming of 1.5 C Above Pre-Industrial Levels and Related Global Greenhouse gas Emission Pathways, in the Context of Strengthening the Global Response to the Threat of Climate Change.

Matson, P., Clark, W. C., \& Andersson, K. (2016). Pursuing sustainability: a guide to the science and practice. Princeton University Press.

Metcalf, L., \& Benn, S. (2013). Leadership for Sustainability: An Evolution of Leadership Ability. Journal of business ethics, 112(3), 369-384. https://doi.org/10.1007/s10551-012-1278-6

Ministry of the Environment. (2014). Sweden's sixth national communication on climate change. Retrieved from https://www.government.se/contentassets/94d274fef8ef470a9b6901421b50d1d1/swedens-sixth-nationalcommunication-on-climate-change---under-the-united-nations-framework-convention-on-climate-changeds-201411

Missimer, M., Robèrt, K. H., \& Broman, G. (2017). A Strategic Approach to Social Sustainability-Part 2: A Principle-Based Definition. Journal of Cleaner Production, 140, 42-52. https://doi.org/10.1016/j.jclepro.2016.04.059

Page, L., \& Pande, R. (2018). Ending global poverty: why money isn't enough. Journal of Economic Perspectives, 32(4), 173-200. https://doi.org/10.1257/jep.32.4.173

Poonamallee, L. (2007). Sustainability and Solidarity in a Globalized World: The Case of a Local Network Economy in Rural India. ephemera, 419.

Press Trust of India. (2013). Retrieved from https://www.business-standard.com/article/economy-policy/70indians-live-in-rural-areas-census-111071500171_1.html

Quinn, L., \& Dalton, M. (2009). Leading for Sustainability: Implementing the Tasks of Leadership. Corporate Governance: International Journal of Business in Society, 9(1), 21-38. https://doi.org/10.1108/14720700910936038

Raju, G. P., \& Dwivedula, R. (2009). From Poverty to Prosperity-A Case of Social Entrepreneurship in an Indian Village. Studies (IJRS), 16(1).

Robèrt, K. H., Borén, S., Ny, H., \& Broman, G. (2017). A Strategic Approach to Sustainable Transport System Development-Part 1: Attempting a Generic Community Planning Process Model. Journal of Cleaner Production, 140, 53-61. https://doi.org/10.1016/j.jclepro.2016.02.054

Robert, K.-H. (2000). Tools and Concepts for Sustainable Development, How Do They Relate to a General Framework for Sustainable Development, and to Each Others? Journal of Cleaner Production, 8, 243-254. https://doi.org/10.1016/S0959-6526(00)00011-1

Robinson, J. B. (1990). Futures Under Glass: A Recipe for People Who Hate to Predict. Futures, 22(8), 820-842. https://doi.org/10.1016/0016-3287(90)90018-D

Roos, J. (2017). Practical Wisdom: Making and Teaching the Governance Case for Sustainability. Journal of Cleaner Production, 140, 117-124. https://doi.org/10.1016/j.jclepro.2015.10.135

Roy, J., Tscharket, P., Waisman, H., Abdul Halim, S., Antwi-Agyei, P., Dasgupta, P., ... \& Pinho, P. F. (2018). Sustainable Development, Poverty Eradication and Reducing Inequalities.

Singh, H. (1994). Constitutional Base for Panchayati Raj in India: The 73rd Amendment Act. Asian Survey, 34(9), 818-827. https://doi.org/10.2307/2645168

Sohrabi, C., Alsafi, Z., O’Neill, N., Khan, M., Kerwan, A., Al-Jabir, A., ... \& Agha, R. (2020). World Health 
Organization Declares Global Emergency: A Review of the 2019 Novel Coronavirus (COVID-19). International Journal of Surgery. https://doi.org/10.1016/j.ijsu.2020.02.034

Stake, R. E. (1995). The art of case study research. Thousand Oaks, CA: Sage.

Stenbacka, C. (2001). Qualitative Research Requires Quality Concepts of Its Own. Management decision. https://doi.org/10.1108/EUM0000000005801

Subbian, V. (2020). Thirumazhisai Market Ready: Helps reducing Vegetable Prices in Tamil Nadu. Retrieved from https://www.newsbricks.com/tamil-nadu/thirumazhisai-market-ready-from-today/94223

Székely, F., \& Knirsch, M. (2005). Responsible Leadership and Corporate Social Responsibility: Metrics for Sustainable Performance. European Management Journal, 23(6), 628-647. https://doi.org/10.1016/j.emj.2005.10.009

Wapner, P., \& Elver, H. (Eds.). (2016). Reimagining climate change. Routledge. https://doi.org/10.4324/9781315671468

Xu, Y., Ramanathan, V., \& Victor, D. G. (2018). Global Warming Will Happen Faster Than We Think. https://doi.org/10.1038/d41586-018-07586-5

Yin, R. K. (2003). Case study research: Design and methods (3rd ed.). Thousand Oaks, CA: Sage.

\section{Copyrights}

Copyright for this article is retained by the author(s), with first publication rights granted to the journal.

This is an open-access article distributed under the terms and conditions of the Creative Commons Attribution license (http://creativecommons.org/licenses/by/4.0/). 